\title{
Annual Visitation of the National Physical Laboratory.
}

\begin{abstract}
A LARGE number of visitors were present at the National Physical Laboratory on the occasion of the Annual Visitation on June 27. The guests were received by Sir Charles Sherrington, president of the Royal Society and chairman of the General Board; and Sir Joseph Petavel, Director of the Laboratory. As is usual on such occasions, the various departments were thrown open and an interesting series of exhibits was arranged, illustrative
\end{abstract} of the work carried on in the institution.

In the Department of Aerodynamics, exhibits were shown in most of the six wind tunnels. In the largest of these, which has a cross section of I4 $\mathrm{ft}$. $\times 7 \mathrm{ft}$, an aerofoil model was set up showing the methods of measuring the lift and drag. The section of the aerofoil under test was on a scale approximately one-fifth of full size. In another channel were shown additions made to the standard type of balance, whereby for one setting of the model the component forces and moments in three directions can be determined. This represents a considerable saving of time in the process of testing. The discontinuous flow of air past a barrier was demonstrated in an effective manner by means of smoke released into the stream of air before it reached the obstacle. Other exhibits included an aeroplane model showing the method of obtaining the distribution of pressure over the wing, an apparatus used for determining the thrust and torque of model propellers, and an ingenious wind direction finder.

The additions to the Engineering Department, consisting of a large experimental shop and a set of offices, have been completed during the year and have much relieved the congestion. Among the exhibits were two machines for testing the efficiency of spur gears and chain drives. In both of these machines the regenerative principle is made use of, so that the power consumption is only that absorbed by the element under test. Thus, to determine the losses corresponding to an actual transmission of roo h.p., a power of the order of 5 h.p. suffices. The efficiencies can be measured to an accuracy of O.I per cent. A new machine for testing reinforced concrete slabs and columns was also shown. The slab specimens can be tested in sizes up to $\mathrm{I} 6 \mathrm{ft} . \times 6 \mathrm{ft}$. and $\mathrm{I}_{4}$ inches in thickness, and the columns from 8 to 20 feet in length; the maximum load is 60 tons. It was interesting to note that it was found possible to support the columns by means of knife-edge pivots. During the year, a plant has been completed for the production of asphalt road carpets. This enables the constituents to be mixed accurately in the proper proportions, prior to laying and testing in the standard road-testing machine. Other exhibits in this department included apparatus designed. for the measurement of the temperature and pressure of the oil film in lubricated journals, the investigation of heat losses through pipe covers, the determination of the fatigue ranges of stress in materials by the strain method, and for the investigation of the detonation of a mixture of air and liquid fuels in closed vessels.

In the Metallurgical Department, a much-needed extension of space has been provided during the year by the addition of an extra floor on the Wernher building. Considerable attention has been devoted in this Department during recent years to the study of aluminium and its alloys, and examples were shown of an alloy developed at the Laboratory which is specially suitable for aeroplane engines. Pistons and piston rings of this material were on view. A specimen of aluminium was exhibited which had been submicted many times to an alternate treatment of rolling and melting without any effect on its tensile strength. A very effective experiment was shown on specimens of an aluminium-zinc alloy, which were heated in a furnace at a temperature of $370^{\circ} \mathrm{C}$. and then quenched by immersion in water. Within a period of five minutes, a considerable generation of heat occurred-due to the breakdown of an unstable solid phase-which rendered the specimen almost too hot to be held in the hand. An interesting series of micro-photographs, taken during this period, showed the structural changes occurring, which are accompanied by great variation in hardness.

In the section of the department dealing with refractory materials, a new recuperative gas furnace, working under natural draught, and intended for glass melting, was running, while in the section of aeronautical chemistry the viscosity method for characterising deterioration of fabrics was demonstrated. Other exhibits in the Metallurgical Department were a high temperature thermostat arranged for obtaining very slow rates of cooling, and an ingenious relay for controlling furnace currents.

In the Heat Division of the Physics Department, various methods for the measurement of thermal conductivity were demonstrated, These included a new apparatus for dealing with thin sheets of material and for studying the effects of pressure on the thermal conductivity, a large scale apparatus for experiments on insulators for cold storage purposes, and a similar apparatus which has been used for measuring the conductivity of a series of building materials. A method for investigating the convection of heat in transformer oils was shown and also a device for the automatic operation of a ventilating valve with small changes of temperature of the air inside and outside a room. Various types af hygrometers were also exhibited.

In the Thermometry Division a new type of resistance bridge was shown with dials reading to $0 . \mathrm{OOI}^{\circ} \mathrm{C}$., with a platinum thermometer of Io ohms fundamental interval.

In the Radiology Division apparatus designed for the X-ray spectroscopic investigation of structure of materials, the measurement of radium salts, the standardising of barium platino-cyanide pastilles, the investigation of protective values of X-ray materials, and the $\mathrm{X}$-ray examination of metals were exhibited.

In the Optics Division, various types of apparatus for measurement and specification of colour were shown. These included a Nutting monochromatic colorimeter, a Lovibond tintometer, a Bawtree colorimeter, and a trichromatic colorimeter for standardisation purposes designed and constructed at the Laboratory. In the latter instrument the mixing of the three primary colours is accomplished by rotating a periscopic prism which passes rapidly in front of three sectorial openings of variable angles in which the coloured filters are placed. Among the exhibits in this division was also a differential refractometer for liquids having nearly the same refractive index, while a new immersion method for measuring the internal bore of a glass tube was also demonstrated.

The Metrolögy Department (Glass Testing Section) showed a new equipment designed for the accurate calibration of hydrometers against a hydrostatic balance. The liquid in which the hydrometer is immersed is surrounded by a water bath controlled by a thermostat. The whole of this apparatus can be moved under a special balance from the scale pans of which are suspended two plummets of the same mass

NO. 27.50, VOL. I IO] 
but differing in volume by roo c.c. The density of the liquid is thus obtained directly by weighing and is compared with the hydrometer under investigation. The balance is of special construction and is provided with inertia bobs at the ends of the arms to counteract the damping due to the movement of the plummets through the liquid. Other exhibits in the Metrology Department included a series of instruments for the precision measurement of engineers' gauges and a vertical interference apparatus for testing the flatness of surfaces, line standards and comparators.

In the Froude National Tank experiments to determine the resistance of a ship form in artificially created waves, and the method of taking continuous records of resistance, pitching angle and pitching period were demonstrated. The object of this work is to obtain data as to the loss of speed of different designs of ships under service conditions. It is interesting to note in this connexion that observations of full size ships have been taken by members of the staff in voyages across the Atlantic in three types of vessels, liners, cargo steamers, and oil tankers. Apparatus was also shown for determining forces on a ship's rudder, the manœuvring power of a ship's form, and the resistance of a seaplane model on the surface of the water.

Many interesting exhibits were on view in the various sections of the Electricity Department. The Photometry Division showed a method of determining the spectral distribution of energy in arcs having cores of different materials, and of measuring the transmission ratios of coloured glasses intended as standards for ships' navigation lights.

The Alternating Current Section demonstrated the speed regulation of a D.C. motor by means of a relatively small phonic motor directly coupled to it. The Direct Current Section showed apparatus for experiments on moulded insulators and other insulating materials, tests on buried cables and on energy losses in a 3 -core cable with three-phase current.

In the Standards Section, an air gap for dielectric tests on mica and thin sheet materials was shown. This consists of very accurately flat steel plates I2 $\mathrm{cms}$. in diameter, separated by distance pieces of quartz, so as to give an accurately parallel gap. The apparatus can be taken apart and the gap reproduced to within $0 \cdot 000 \mathrm{~mm}$. In connexion with the abovementioned apparatus, a machine of the optical lever type has been evolved for measuring the thickness from point to point of sheets of mica or other thin material.

A standard multivibrator apparatus for radiofrequencies was shown by the same section. In this apparatus a wave with a sharp peak is produced, having a frequency of Iooo per sec. From this, by the help of a highly resonant circuit, every harmonic up to the hundredth may be picked out, thus providing a series of accurately spaced radio-frequencies. The fundamental is kept constant to I part in Ioo, by a tuning-fork control. A second multivibrator, which can be controlled from the first one, has a fundamental of 30,000 per second and gives a further series up to $\mathrm{I}, 000,000$ per second.

In the Wireless Section, directional measurements of spark and continuous wave stations were shown, the photographic reception of signals on a string galvanometer, and a new type of thermo-junction ammeter for high frequency.

\section{Agricultural Research in Great Britain.}

THE "assistant principal" at the Ministry of Agriculture, Mr. V. E. Wilkins, has prepared a valuable pamphlet, ${ }^{1}$ which gives a useful account of the various forms of agricultural research that are being supported financially by the State. As is well known, the Ministry decided to concentrate research at definite institutions; Rothamsted is concerned with plant nutrition, soil problems, and plant pathology; Cambridge has entrusted to it plant and animal breeding, and animal nutrition; Long Ashton, a branch of the University of Bristol, deals with fruit growing and preserving ; plant physiology is dealt with at the research institute attached to the Imperial College of Science ; dairying at Reading ; animal pathology at the Royal Veterinary College; agricultural zoology at Birmingham; helminthology at the London School of Tropical Medicine; agricultural economics in Oxford; plant breeding, with particular reference to Wales, at Aberystwyth; fruit growing and hops at East Malling; and nursery and market gardening at Cheshunt. Besides these research institutes and stations the Ministry has set up a system of advisory centres from which information in respect of specific subjects is disseminated by advisory officers who also, in many cases, undertake a certain amount of research.

(a) The Soil and its Effect on Plant Growth.-This fundamental subject has been entrusted to the Rothamsted Experimental Station, which is concerned, among other things, with the examination of the soil in its relation to bacteria and protozoa, and an account is given of the arduous nature of the research along these lines. The nitrification of

1 "Ministry of Agriculture and Fisheries. Agricultural Research and the Farmer: A Record of Recent Achievement." By V: E. Wilkins. Pp I68. (London: H.M. Stationery Office, I922.) 2s. $6 d$. net. organic nitrogen alone has demanded the services of eight research workers, who in many cases have worked night- and day-shifts. An interesting form of investigation undertaken at this station is concerned with the production of artificial farmyard manure. During the later stages of the war, and subsequently, until the agricultural policy of the Government was altered, there was a prospect of a superabundance of straw, more, in fact, than could be dealt with as food and litter by farm animals. The Rothamsted investigators set about devising a means of converting this straw directly into farmyard manure, and the results are most encouraging, although now, with the reduced area of tillage land, the necessity for such conversion is no longer pressing.

At the same station much work has been done on the influence of colloids on the water-content of soil, and on the mechanical operations concerned with tillage. Most ingenious electrical methods are also being exploited to determine the relation between soil acidity and crop production, and the list of publications that have been issued from Rothamsted during 1920 and I92I shows the extraordinarily varied character of the work being conducted at this famous station.

(b) Plant Breeding.-The problems that are being investigated along this line are concerned with the baking qualities or strength of English wheat, with the production of cereals possessed of a straw stiff enough to stand up under adverse circumstances, with immunity to disease, with the increase of the number of grains in the ear, with the production of hardier varieties of winter oats, with the relationship of nitrogen in barley grain to the quality of the produce, and with the production of potatoes immune to wart disease. Thesé problems are being dealt

$$
\text { NO. } 275 \text { O, VOL. I IO] }
$$

